\title{
Respiratory variations of inferior vena cava diameter to predict fluid responsiveness in spontaneously breathing patients with acute circulatory failure: need for a cautious use
}

Laurent Muller ${ }^{1 *}$, Xavier Bobbia ${ }^{1}$, Mehdi Toumi ${ }^{1}$, Guillaume Louart ${ }^{1}$, Nicolas Molinari ${ }^{2}$, Benoit Ragonnet ${ }^{3}$, Hervé Quintard ${ }^{4}$, Marc Leone ${ }^{3}$, Lana Zoric ${ }^{1}$, Jean Yves Lefrant ${ }^{1}$ and the AzuRea group

\begin{abstract}
Introduction: To investigate whether respiratory variation of inferior vena cava diameter (cIVC) predict fluid responsiveness in spontaneously breathing patients with acute circulatory failure (ACF).

Methods: Forty patients with ACF and spontaneous breathing were included. Response to fluid challenge was defined as a 15\% increase of subaortic velocity time index (VTI) measured by transthoracic echocardiography. Inferior vena cava diameters were recorded by a subcostal view using M Mode. The cIVC was calculated as follows: (Dmax - Dmin/Dmax) $\times 100$ and then receiver operating characteristic (ROC) curves were generated for CIVC, baseline VTI, E wave velocity, E/A and E/Ea ratios.

Results: Among 40 included patients, 20 (50\%) were responders (R). The causes of ACF were sepsis $(n=24)$, haemorrhage $(n=11)$, and dehydration $(n=5)$. The area under the ROC curve for CIVC was 0.77 (95\% Cl: $0.60-$ 0.88). The best cutoff value was $40 \%$ ( $\mathrm{Se}=70 \%, \mathrm{Sp}=80 \%$ ). The AUC of the ROC curves for baseline $\mathrm{E}$ wave velocity, VTI, E/A ratio, E/Ea ratio were 0.83 (95\% Cl: 0.68-0.93), 0.78 (95\% Cl: 0.61-0.88), 0.76 (95\% Cl: 0.59-0.89), 0.58 (95\% Cl: 0.41-0.75), respectively. The differences between AUC the ROC curves for cIVC and baseline $E$ wave velocity, baseline VTI, baseline E/A ratio, and baseline E/Ea ratio were not statistically different $(p=0.46, p=0.99$, $p=1.00, p=0.26$, respectively).
\end{abstract}

Conclusion: In spontaneously breathing patients with ACF, high cIVC values $(>40 \%)$ are usually associated with fluid responsiveness while low values $(<40 \%)$ do not exclude fluid responsiveness.

\section{Introduction}

Assessment of fluid responsiveness remains a daily therapeutic challenge in spontaneously breathing critically ill patients with acute circulatory failure (ACF) [1]. In mechanically ventilated patients, one of the best ways to assess fluid responsiveness is to quantify respiratory variation of arterial pulse pressure or aortic velocities recorded by esophageal Doppler or echocardiography (dynamic indices) [2-5]. However, dynamic indices are not valid in spontaneously breathing patients [6,7]. Static

\footnotetext{
* Correspondence: laurent.muller27@orange.fr

'Department of Anesthesiology, Emergency and Critical Care Medicine, Intensive Care unit, Nimes University Hospital, place du Pr Debré 30029, Nîmes, France

Full list of author information is available at the end of the article
}

preload indices like central venous pressure (CVP) do not represent a reasonable alternative for two main reasons. First, central filling pressures are not systematically available in the initial phase of shock because a central venous catheter is not always available. Second, it has been clearly shown that static indices do not accurately predict fluid responsiveness, except for values $<5 \mathrm{mmHg}$ [8-11]. Therefore, fluid challenge is often used to test fluid responsiveness [12]. Nevertheless, about $50 \%$ of fluid challenges are not justified [2]. This exposes patients to deleterious fluid overload. The passive legraising (PLR) test has been developed as a non-invasive technique to perform fluid challenge. By mobilizing the venous blood content of the leg, PLR mimics a $300 \mathrm{ml}$
C Biomed Central

() 2012 Muller et al.; licensee BioMed Central Ltd. This is an open access article distributed under the terms of the Creative Commons Attribution License (http://creativecommons.org/licenses/by/2.0), which permits unrestricted use, distribution, and reproduction in any medium, provided the original work is properly cited. 
fluid infusion that accurately predicts fluid responsiveness $[13,14]$, even in spontaneously breathing patients [15]. However, in case of severe pelvic or leg trauma, the PLR test cannot be performed. We recently proposed using a $100 \mathrm{~mL}$ fluid challenge to test fluid responsiveness in order to avoid fluid overload, but this was validated only in mechanically ventilated patients [16].

Use of respiratory IVC diameter variation (cIVC) is very popular because it is very easy to record, and needs a short learning curve, even for non-cardiologist residents or physicians [17]. cIVC has been shown to accurately predict fluid responsiveness in mechanically ventilated critically ill patients [18-20]. As with any dynamic parameter, there could be objection to using cIVC in patients with spontaneous ventilation. Nevertheless, in spontaneously breathing patients, cIVC is widely used because it correlates to CVP even if CVP is, however, poorly predictive of fluid responsiveness $[21,22]$. cIVC is correlated to fluid removal after chronic dialysis in nephrology outpatients $[17,23]$, or during continuous hemofiltration in non-ventilated ICU patients with acute severe heart failure [24]. The monitoring of blood volume is not the same as evaluating fluid responsiveness, but there is a risk of confusing the two concepts. In clinical practice, physicians can then use cIVC to predict fluid responsiveness in spontaneously breathing patients because it correlates with blood volume. Therefore, it can be questioned if cIVC diameter can effectively predict fluid responsiveness in spontaneously breathing patients and if there are limitations to this technique.

Therefore, the present study was aimed at assessing the usefulness of cIVC recorded by transthoracic echocardiography (TTE) to predict fluid responsiveness in spontaneously breathing critically ill patients with acute circulatory failure.

\section{Materials and methods Patients}

This observational study was approved by our local institutional review board (Nîmes University hospital review board, reference number 110702). It was stated that informed consent was not necessary; nevertheless, the patients or their relatives were orally informed, in accordance with French legislation.

The study was conducted in a 16-bed ICU of a university hospital within a 24-month period (April 2009 to April 2011). Forty patients with ACF were prospectively included within the study period. ACF was defined as mean arterial pressure (MAP) $<65 \mathrm{mmHg}$, urine output $<0.5 \mathrm{~mL} / \mathrm{Kg} / \mathrm{h}$, tachycardia, mottled skin and/or biological signs of hypoperfusion (arterial blood lactate $>2$ $\mathrm{mmol} / \mathrm{L}$ ). We excluded patients in whom fluid challenge would be deleterious: those with clinical evidence of pulmonary edema, echocardiographic evidence of right ventricular (RV) failure (right telediastolic ventricle area to left telediastolic ventricle area ratio > 1) [25] or echocardiographic evidence of elevated left atrial pressure (mitral inflow early (E) wave to atrial (A) wave ratio $>2$ ) [26-28]. The decision was based on the opinion of the senior physician in charge of the ICU.

\section{Measurements}

For each patient, the following data were recorded: diagnosis, age (years), weight $(\mathrm{Kg})$, height $(\mathrm{cm})$, Acute Physiology and Chronic Health Evaluation (APACHE)-II score at admission, MAP (mmHg), heart rate (HR, bpm) and CVP $(\mathrm{mmHg})$ when available.

Echocardiographic measurements were performed by four trained (level 3 [29]) operators (LM, XB, MT, GL), for whom the intra- and interobserver variability for the velocity time index (VTI) $=4$ and $5 \%$, respectively [16]), using a Vivid S6 machine, General Electrics (GE Healthcare, Chalfont St Giles, UK).

IVC was observed by a subcostal long axis view. In order to differentiate the aorta and IVC, the junction between the IVC and the right atrium was systematically assessed. A pulse wave Doppler of the IVC was also recorded in order to verify the presence of a typical venous flow spectrum. A time-motion record of the IVC diameter was generated by $\mathrm{M}$-mode imaging at 2 to $3 \mathrm{~cm}$ from the right atrium [18,30]. Maximum and minimum IVC diameters (Dmax and Dmin, respectively) were measured over a single ventilatory cycle. The IVC collapsibility index (cIVC) was used as the primary endpoint [31]. This method was previously validated in spontaneously breathing patients undergoing renal replacement therapy [24]. The cIVC was defined as follows:

$\mathrm{cIVC}=($ Dmax $-\mathrm{Dmin}) / \mathrm{Dmax}$.

cIVC was expressed as a percentage. In addition, to be sure that the formula:

$\left(\right.$ Dmax $-\operatorname{Dmin} /\left((D m a x+D m i n) / 2=\operatorname{cIVC}_{2}\right)$

could not be more informative, we also built its respective receiver operator characteristic (ROC) curves.

The VTI was recorded by pulse waved Doppler on a five-chamber apical view [32]. For each step of the study, the VTI $(\mathrm{cm})$ was measured in triplicate. The obtained values were averaged for its determination.

In parallel, the left ventricular filling pressures were assessed using the mitral inflow coupled to tissue Doppler imaging. The transmitral diastolic inflow, or E/A velocity ratio (velocity of the $\mathrm{E}$ wave/velocity of the $\mathrm{A}$ wave in $\mathrm{cm} / \mathrm{s}$ ) was recorded by pulse Doppler in the apical four-chamber view at the distal extremity of the mitral leaflets [26,33]. In the same view, protodiastolic tissue Doppler velocity was recorded at the lateral annular mitral annulus (Ea wave, $\mathrm{cm} / \mathrm{s}$ ) [33]. The ratio between $\mathrm{E}$ and $\mathrm{Ea}$ wave velocities (E/Ea ratio) was 
calculated as an index of left ventriclular filling pressure $[33,34]$.

Right ventriclular dilatation was defined as a right to left telediastolic ventriclular area ratio $>1$ (RV/LV area ratio) [25]. Left ventriclular systolic function was visually quantified as previously described [35]. Lastly, the shortening diameter fraction was determined in the $M$ mode and parasternal long axis view.

\section{Protocol}

After ruling out the exclusion criteria, a first echocardiography was performed in all spontaneously breathing patients with ACF. At this time $\left(\mathrm{T}_{0}\right), \mathrm{HR}, \mathrm{MAP}, \mathrm{E}, \mathrm{A}$, and Ea velocities, E/A ratio, E/Ea ratio, and subaortic VTI were recorded. Then a fluid challenge was performed with $500 \mathrm{~mL}$ of a 6\% 130/0.4 hydroxyethylstarch solution (Voluven ${ }^{\circledR}$, Fresenius-Kabi, Louviers, France) infused over 15 minutes. After this fluid challenge (at $\mathrm{T}_{15}$ ), HR, MAP, E, A, and Ea velocities, E/A ratio, E/Ea ratio, and subaortic VTI were recorded. Fluid responsiveness was defined as an increase in the subaortic VTI $\geq 15 \%$ after the fluid challenge. This served to split the patients into responders (R) and non-responders (NR) $[15,16,36]$. Of note, the investigators were not blinded.

\section{Statistical analysis}

Data are expressed as medians with the $5^{\text {th }}$ and $95^{\text {th }}$ percentiles. For the comparisons between $\mathrm{R}$ and NR, Mann-Whitney, Chi square and Fisher exact tests were performed when appropriate. ROC curves were constructed to evaluate the ability of cIVC to predict fluid responsiveness. When the AUC was greater than 0.5, the best cutoff value was defined by the closest value to the Youden index [37]. ROC curves of $\mathrm{E}$ wave velocity, E/A ratio, E/Ea ratio, and CVP were compared to the ROC curve of the cIVC for each individual using the Hanley test [38]. Statistical analysis was performed using SAS v 8.1 software (SAS Institute, Cary, NY, USA). All $P$-values were two-tailed and a $P$-value $<0.05$ was considered significant. We assumed that cIVC would be clinically relevant if the $95 \%$ confidence interval (CI) of its area under the curve (AUC) was $>0.75$, corresponding to an AUC of a good clinical tool as reported by Ray et al. [39]. For this purpose, 39 patients had to be included. A bootstrap analysis was used to calculate precise confidence intervals. Bootstrapping is a method for assigning measures of accuracy to sample estimates and allows estimation of the sampling distribution [40].

\section{Results}

Among 40 spontaneously breathing patients with ACF included in this analysis, $20(50 \%)$ responded to the fluid challenge. Regarding demographics and disease severity, no difference was observed between R and NR (Table 1). The causes of the ACF are detailed in Table 2.

Individual values of cIVC according to the fluid responsiveness are shown in Figure 1. The AUC of the ROC curve for cIVC was 0.77 (95\% CI 0.60, 0.88, $P=$ 0.08 compared to 0.5 ) (Figure 2). The best cutoff value was $40 \%$. For cIVC, the positive predictive value, negative predictive value, positive likelihood ratio, and negative likelihood ratio was $72 \%, 83 \%, 4.67$, and 0.35 , respectively. For cIVC, accuracy was 0.75 and Youden's index was 0.5 . The AUC for baseline $\mathrm{E}$ wave velocity was 0.83 (95\% CI 0.68 to $0.93, P=0.07$ compared to $0.5)$. For $E$ wave velocity, the best cutoff value was 0.7 (sensitivity $67 \%$, specificity $90 \%$ ), and the positive predictive value, negative predictive value, positive likelihood ratio, and negative likelihood ratio was $84 \%, 83 \%, 6.67$, and 0.37 , respectively. For E wave velocity, Youden's index was 0.64 and accuracy 0.88 .

The AUC for the VTI, E/A ratio, and E/Ea ratio was 0.78 (95\% CI 0.61, 0.88), 0.76 (95\% CI 0.59, 0.89), and 0.58 (95\% CI $0.41,0.75)$ respectively. There was no difference between the AUC of the ROC curve for cIVC and $\mathrm{E}$ wave velocity, VTI, E/A ratio or E/Ea ratio $(P=$ $0.46,0.99,1.00$, and 0.26 , respectively).

Because the data set can be considered as low, and to validate our CIs, we completed the statistical analysis with a bootstrap technique. This technique accurately predicted the rate and statistical significance of the AUC difference on 1000 bootstrapped samples from the original study population. This shows a CI for $\mathrm{CIVC}=0.59$ to 0.90 , median 0.83 , and for $\mathrm{E}$ wave velocity, $\mathrm{CI}=0.68$ to 0.95 , median 0.77 . Bootstrap analysis tends to confirm our basic results.

When using the formula (Dmax - Dmin/((Dmax + $\mathrm{Dmin}) / 2)\left(\mathrm{cIVC}_{2}\right)$, the AUC of ROC curve for $\mathrm{cIVC}_{2}$ was 0.77 (95\% CI $0.60,0.88)$. The best cutoff value was $25 \%$. The AUC of the ROC curve for baseline $\mathrm{E}$ wave velocity, VTI, E/A ratio, and E/Ea ratio were 0.83 (95\% CI $0.68,0.93), 0.78$ (95\% CI $0.61,0.88), 0.76$ (95\% CI $0.59,0.89)$, and 0.58 (95\% CI $0.41,0.75)$, respectively. There were no statistical differences between the AUC for $\mathrm{CIVC}_{2}$ and $\mathrm{E}$ wave velocity, VTI, E/A ratio, and E/Ea ratio $(P=0.46,0.99,1.00$, and 0.26 , respectively).

\section{Discussion}

Because the AUC of the ROC curve for cIVC was 0.77 (95\% CI $0.60,0.88)$, the present study shows that cIVC cannot reliably (inferior limit of $\mathrm{CI}<0.75$ ) predict fluid responsiveness in spontaneously breathing patients with ACF. More precisely, a cIVC value below $40 \%$ cannot exclude fluid responsiveness while patients with cIVC above $40 \%$ are more likely to respond to fluid challenge. The $40 \%$ cutoff value is in agreement with recent studies [22]. 
Table 1 Characteristics of the general population and comparison between responders and non-responders at baseline (before fluid challenge)

\begin{tabular}{|c|c|c|c|c|}
\hline & $\begin{array}{l}\text { All patients } \\
(n=40)\end{array}$ & $\begin{array}{l}\text { Responders } \\
(n=20)\end{array}$ & $\begin{array}{l}\text { Non-responders } \\
\quad(n=20)\end{array}$ & $P$-value \\
\hline Age, years & $63(56,70)$ & $61(49,70)$ & $66(53,75)$ & 0.58 \\
\hline Weight, Kg & $72(65,77$ & $67(63,76)$ & $76(63,88)$ & 0.14 \\
\hline Height, cm & $169(164,173)$ & $170(162,176)$ & $168(160,173)$ & 0.38 \\
\hline APACHE II score & $17(14,23)$ & $18(14,29)$ & $14(11,21)$ & 0.30 \\
\hline Heart rate, bpm & $101(91,116)$ & $101(91,125)$ & $103(79,121)$ & 0.78 \\
\hline Mean arterial pressure, $\mathrm{mmHg}$ & $71(66,77)$ & $70(61,88)$ & $72(65,87)$ & 0.56 \\
\hline LVEF, \% & $55(50,60)$ & $55(50,60)$ & $55(47,60)$ & 0.41 \\
\hline Velocity time index, $\mathrm{cm}$ & $16(14,18)$ & $14(12,16)$ & $17(15,21)$ & $<0.01$ \\
\hline E velocity, $\mathrm{cm} / \mathrm{s}$ & $75(70,80)$ & $65(53,76)$ & $82(75,93)$ & $<0.01$ \\
\hline E/A velocity ratio & $0,9(0.8,1.1)$ & $0,8(0,6,1,1)$ & $1,0(0,8,1,4)$ & $<0.01$ \\
\hline Ea velocity, $\mathrm{cm} / \mathrm{s}$ & $12(10,13)$ & $12(9,14)$ & $11(9,15)$ & 0.79 \\
\hline E/Ea velocity ratio & $6(5,8)$ & $5(5,10)$ & $7(5,8)$ & 0.40 \\
\hline cIVC, \% & $34(16,64)$ & $64(28,100)$ & $19(5,35)$ & $<0.01$ \\
\hline
\end{tabular}

Data are expressed in medians with $5^{\text {th }}$ and $95^{\text {th }}$ percentiles. APACHE: Acute Physiology and Chronic Health Evaluation; clVC, collapsibility index of the inferior vena cava.

The first explanation for these imperfect results is that, as previously suggested, cIVC is a dynamic preload index. In contrast with findings reported in mechanically ventilated septic patients, dynamic parameters have been shown to be ineffective to predict fluid responsiveness in spontaneous breathing patients [6,7]. Spontaneous ventilation implies a very wide range of breathing patterns. In patients with spontaneous ventilation, respiratory variations are highly variable from one cycle to another in a given patient and between different patients. Then, influence of breathing pattern on cIVC is also variable. The present results indirectly confirm that spontaneous breathing is a natural limit for the use of a dynamic parameter.

Because previous studies have reported a good correlation between cIVC and blood volume removal during hemodialysis $[17,24]$ or during blood donation [41], the inability of cIVC to predict fluid responsiveness may be surprising in spontaneously breathing patients with ACF. However, monitoring blood volume during blood removal is not the same as predicting fluid responsiveness. It has

Table 2 Causes of acute circulatory failure

\begin{tabular}{cc}
\hline Pathology & Number of patients (\%) \\
\hline Sepsis & $24(60)$ \\
Intra-abdominal infection & 10 \\
Pulmonary infection & 9 \\
Pyelonephritis & 5 \\
Bleeding & $11(28)$ \\
Postoperative & 7 \\
Trauma & 4 \\
Dehydration & $5(13)$ \\
\hline
\end{tabular}

The total percentage is different from $100 \%$ because specific percentages were rounded. been shown that there is a good correlation between high cIVC value and low CVP value [21,22,42]. A low CVP value $(<7 \mathrm{mmHg})$ could be considered a good indicator of fluid responsiveness [11], corresponding to high values of cIVC (specificity $=80 \%$ ). In contrast, lower values of cIVC values are poorly predictive, corresponding to higher values of CVP $[8,9]$.

The conditions of measurement of cIVC could be discussed. In the present study, the IVC diameter was measured by $\mathrm{M}$ mode at 2 or $3 \mathrm{~cm}$ from the right atrium, as described in previous studies $[17,18,22]$. However, Wallace $e t$ al. [43] recently showed that in spontaneously breathing healthy volunteers, variations of IVC diameter were significantly lower when recorded closed to the

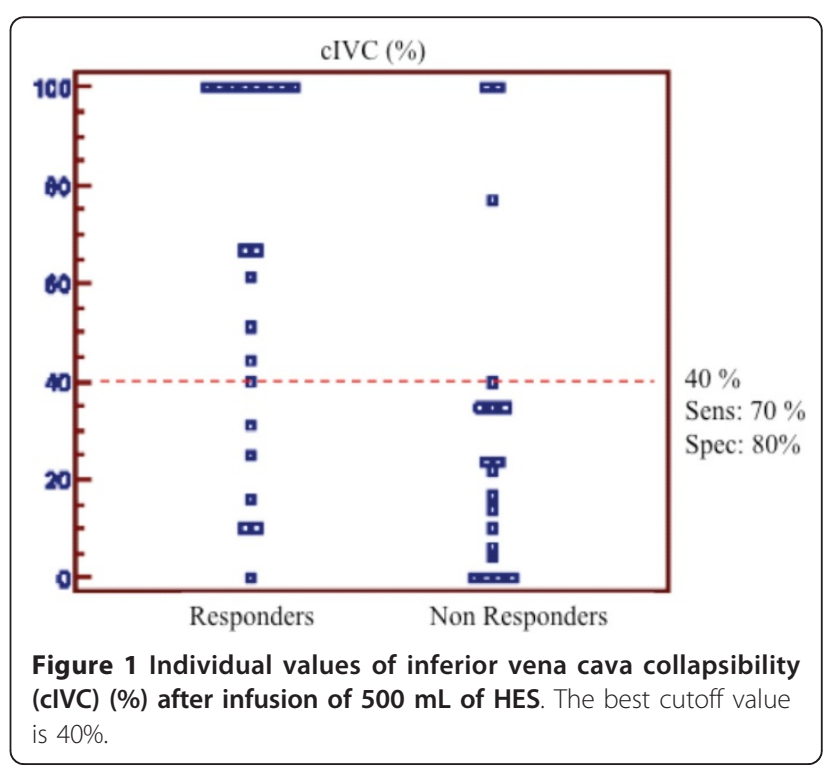




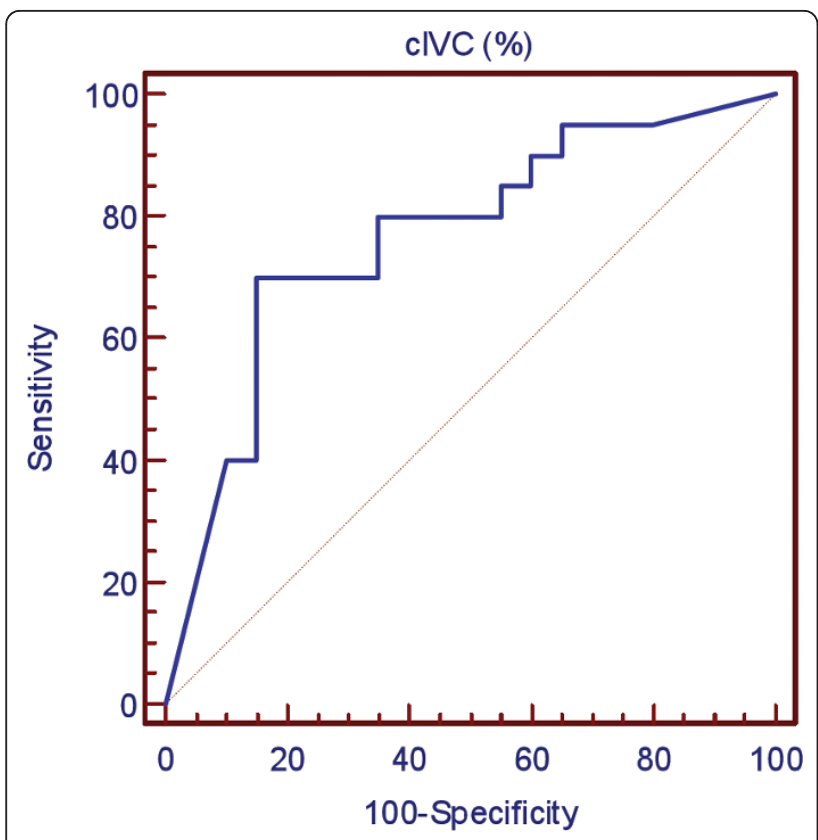

Figure 2 Receiver operator characteristic (ROC) curve for inferior vena cava collapsibility (cIVC) (\%) after infusion of $\mathbf{5 0 0}$ $\mathrm{mL}$ of HES. Area under the ROC curve was 0.77 ( $95 \% \mathrm{Cl} 0.60,0.88)$

right atria $(\mathrm{cIVC}=20 \%)$ than when recorded $2 \mathrm{~cm}$ caudal to the hepatic vein inlet ( $\operatorname{cIVC}=30 \%, P=0.03$ ) or at the level of the left renal vein $(\mathrm{cIVC}=30 \%, P=0.002)$ [43]. This finding would explain our high rate of false negative results. This hypothesis needs to be tested in further studies. A second methodological concern is that cIVC may be influenced by the magnitude of respiratory movements, especially in the case of dyspnea, a typical feature in patients with circulatory failure and/or shock. As discussed above, the wide range of breathing patterns observed in spontaneously breathing critically ill patients is probably confusing. Kimura et al. [44] recently showed that breathing manner significantly affects cIVC in spontaneously breathing volunteers. This could explain why three patients in the present study showed high cIVC values without response to fluid challenge, but this hypothesis cannot actually be verified.

The choice of the formula for cIVC could also be debated. As described in the method section, we used the cIVC formula (Dmax - Dmin/Dmax). One could argue that the cIVC formula used by an other group [18] $\left(\mathrm{cIVC}_{2}\right)$ could better analyse the variability of IVC ventilatory variations. After testing the two formulas, we did not observe any difference between the two indices. Then, the type of formula is not a major determinant of IVC respiratory variation analysis.

Mitral Doppler inflow patterns allow indirect assessment of left ventricular filling pressure [26]. In particular, E wave velocity is correlated to patients with pulmonary capillary wedge pressure [26,27]. In outpatients with preserved systolic function but significant ischemic or hypertensive heart disease, low $(<60 \mathrm{~cm} / \mathrm{s})$ or high $(>90 \mathrm{~cm} / \mathrm{s})$ $\mathrm{E}$ wave velocities are correlated with low and high left ventricular end diastolic pressure (LVEDP), respectively [45]. Similarly, our findings show that baseline E wave velocity was also significantly lower in $\mathrm{R}$ at $65 \mathrm{~cm} / \mathrm{s}(53$, 76) than in NR patients at $82 \mathrm{~cm} / \mathrm{s}(75,93)(P=0.0005)$. Even if it was not the primary objective of this study, this suggests that $\mathrm{E}$ wave velocity $<70 \mathrm{~cm} / \mathrm{s}$ (best cutoff value) could help to identify responders A spontaneously breathing patients.

\section{Study limitations}

The present study has some limitations. First, the physicians were not blinded. Second, the patients were not consecutive. Indeed, to be included, the study required the presence of an eligible patient and the presence of a physician certified in cardiac echography. As most patients admitted to our ICU were mechanically ventilated, 2 years were needed to complete the present study. Third, the PLR test could be used in order to avoid unnecessary fluid infusion. Performing a PLR test with echocardiography to assess fluid responsiveness is validated in spontaneous breathing patients [15]. In the present study, a PLR test was not used because it is not a routine test in our ICU. Finally, the heterogeneous population of patients may have affected our findings. We cannot exclude that cIVC could be more or less accurate in a specific population of patients such as those with trauma or sepsis.

In summary, cIVC moderately predicted fluid responsiveness in spontaneously breathing patients with ACF. In patients with a low cIVC value $(<40 \%)$, fluid responsiveness cannot be excluded, while patients with cIVC above $40 \%$ are more likely to respond to fluid challenge. Then, despite its simplicity of use, cIVC should be used with caution in spontaneously breathing patients with ACF. Additionally, our results also suggest that low values of $\mathrm{E}$ wave velocity $(<0.7 \mathrm{~m} / \mathrm{s})$ could be used to identify responders to fluid challenge.

\section{Conclusions}

In spontaneously breathing patients with $\mathrm{ACF}$, despite its apparent simplicity, cIVC should be interpreted with caution. A high cIVC value ( $>40 \%)$ is usually associated with fluid responsiveness while low values $(<40 \%)$ do not exclude fluid responsiveness.

\section{Key messages}

- As demonstrated in controlled mechanical ventilation, large respiratory variations (> 40\%) of inferior vena cava diameter are usually associated with a positive response to fluid challenge in spontaneous breathing patients. 
- In contrast to what was demonstrated in controlled mechanical ventilation, low variations $(<40 \%)$ of IVC diameter cannot rule out a need for fluid therapy in spontaneously breathing patients with acute circulatory failure.

- In such situations, a low value of $\mathrm{E}$ wave velocity $(<0.7 \mathrm{~m} / \mathrm{S})$ is usually associated with positive response to fluid challenge.

\section{List of Abbreviations}

ACF: acute circulatory failure; APACHE: Acute Physiology and Chronic Health Evaluation; AUC: area under curve; Cl: confidence interval; CIVC: respiratory variation of inferior vena cava diameter, collapsibility of inferior vena cava diameter; CVP: central venous pressure; HR: heart rate; ICU: intensive care unit; LV: left ventricle; LVEDP: left ventricle end diastolic pressure; MAP: mean arterial pressure; NR: non-responders; PLR: passive leg raising; R: responders; ROC: receiver operating characteristic; RV: right ventricle; TTE: transthoracic echocardiography; VTI: velocity time index.

\section{Author details}

${ }^{1}$ Department of Anesthesiology, Emergency and Critical Care Medicine, Intensive Care unit, Nimes University Hospital, place du Pr Debré 30029, Nimes, France. ${ }^{2}$ Department of Biostatistics, UMR 729 MISTEA, Montpellier University Hospital, avenue Gaston Giraud, 34093 Montpellier, France. ${ }^{3}$ Department of Anesthesiology and Critical Care Medicine, Nord Hospital, Assistance Publique - Hôpitaux de Marseille, Aix-Marseille University, 13015, Marseille, France. ${ }^{4}$ Intensive Care Unit, Saint Roch Hospital, Nice-Antipolis University Hospital, 5 rue Pierre Devoluy 06000, Nice, France.

\section{Authors' contributions}

LM conceived the study, wrote the manuscript and performed some echocardiography exams. JYL was the director of this research project and participated in the writing of this manuscript. XB, MT and GL performed some echocardiography exams. NM was responsible for the statistical analysis. BR, HQ and ML significantly helped to draft the manuscript. LZ checked the English language. All authors read and approved the final manuscript.

\section{Competing interests}

The authors declare that they have no competing interests.

Received: 29 March 2012 Revised: 8 August 2012

Accepted: 8 October 2012 Published: 8 October 2012

\section{References}

1. Vincent JL, Rhodes A, Perel A, Martin GS, Della Rocca G, Vallet B, Pinsky MR, Hofer CK, Teboul JL, de Boode WP, Scolletta S, Vieillard-Baron A, De Backer D, Walley KR, Maggiorini M, Singer M: Clinical review: Update on hemodynamic monitoring-a consensus of 16. Crit Care 2011, 15:229.

2. Michard F, Teboul JL: Predicting fluid responsiveness in ICU patients: a critical analysis of the evidence. Chest 2002, 121:2000-2008.

3. Michard F, Boussat S, Chemla D, Anguel N, Mercat A, Lecarpentier Y, Richard C, Pinsky MR, Teboul JL: Relation between respiratory changes in arterial pulse pressure and fluid responsiveness in septic patients with acute circulatory failure. Am J Respir Crit Care Med 2000, 162:134-138.

4. Feissel M, Michard F, Mangin I, Ruyer O, Faller JP, Teboul JL: Respiratory changes in aortic blood velocity as an indicator of fluid responsiveness in ventilated patients with septic shock. Chest 2001, 119:867-873.

5. Monnet X, Rienzo M, Osman D, Anguel N, Richard C, Pinsky MR, Teboul JL: Esophageal Doppler monitoring predicts fluid responsiveness in critically ill ventilated patients. Intensive Care Med 2005, 31:1195-1201.

6. Michard F: Changes in arterial pressure during mechanical ventilation. Anesthesiology 2005, 103:419-428.

7. Soubrier S, Saulnier F, Hubert H, Delour P, Lenci H, Onimus T, Nseir S, Durocher A: Can dynamic indicators help the prediction of fluid responsiveness in spontaneously breathing critically ill patients? Intensive Care Med 2007, 33:1117-1124.
8. Marik PE, Cavallazzi R, Vasu T, Hirani A: Dynamic changes in arterial waveform derived variables and fluid responsiveness in mechanically ventilated patients: a systematic review of the literature. Crit Care Med 2009, 37:2642-2647.

9. Osman D, Ridel C, Ray P, Monnet X, Anguel N, Richard C, Teboul JL: Cardiac filling pressures are not appropriate to predict hemodynamic response to volume challenge. Crit Care Med 2007, 35:64-68.

10. Teboul JL: SRLF experts recommendations: Indicators of volume resuscitation during circulatory failure. Ann Fr Anesth Reanim 2005, 24:568-576, Article in French.

11. Muller L, Louart G, Bengler C, Fabbro-Peray P, Carr J, Ripart J, de La Coussaye JE, Lefrant JY: The intrathoracic blood volume index as an indicator of fluid responsiveness in critically ill patients with acute circulatory failure: a comparison with central venous pressure. Anesth Analg 2008, 107:607-613.

12. Vincent JL, Weil MH: Fluid challenge revisited. Crit Care Med 2006, 34:1333-1337.

13. Boulain T, Achard JM, Teboul JL, Richard C, Perrotin D, Ginies G: Changes in BP induced by passive leg raising predict response to fluid loading in critically ill patients. Chest 2002, 121:1245-1252.

14. Monnet X, Rienzo M, Osman D, Anguel N, Richard C, Pinsky MR, Teboul JL: Passive leg raising predicts fluid responsiveness in the critically ill. Crit Care Med 2006, 34:1402-1407.

15. Lamia B, Ochagavia A, Monnet X, Chemla D, Richard C, Teboul JL: Echocardiographic prediction of volume responsiveness in critically ill patients with spontaneously breathing activity. Intensive Care Med 2007, 33:1125-1132.

16. Muller L, Toumi M, Bousquet PJ, Riu-Poulenc B, Louart G, Candela D, Zoric L, Suehs C, de La Coussaye JE, Molinari N, Lefrant JY, AzuRéa Group: An increase in aortic blood flow after an infusion of $100 \mathrm{ml}$ colloid over 1 minute can predict fluid responsiveness: the mini-fluid challenge study. Anesthesiology 2011, 115:541-547.

17. Brennan JM, Ronan A, Goonewardena S, Blair JE, Hammes M, Shah D, Vasaiwala S, Kirkpatrick JN, Spencer KT: Handcarried ultrasound measurement of the inferior vena cava for assessment of intravascular volume status in the outpatient hemodialysis clinic. Clin J Am Soc Nephrol 2006, 1:749-753.

18. Feissel M, Michard F, Faller JP, Teboul JL: The respiratory variation in inferior vena cava diameter as a guide to fluid therapy. Intensive Care Med 2004, 30:1834-1837.

19. Caille V, Jabot J, Belliard G, Charron C, Jardin F, Vieillard-Baron A: Hemodynamic effects of passive leg raising: an echocardiographic study in patients with shock. Intensive Care Med 2008, 34:1239-1245.

20. Maizel J, Airapetian N, Lorne E, Tribouilloy C, Massy Z, Slama M: Diagnosis of central hypovolemia by using passive leg raising. Intensive Care Med 2007, 33:1133-1138.

21. Nagdev AD, Merchant RC, Tirado-Gonzalez A, Sisson CA, Murphy MC: Emergency department bedside ultrasonographic measurement of the caval index for noninvasive determination of low central venous pressure. Ann Emerg Med 2010, 55:290-295.

22. Brennan JM, Blair JE, Goonewardena S, Ronan A, Shah D, Vasaiwala S, Kirkpatrick JN, Spencer KT: Reappraisal of the use of inferior vena cava for estimating right atrial pressure. J Am SoC Echocardiogr 2007, 20:857-861.

23. Cheriex EC, Leunissen KM, Janssen JH, Mooy JM, van Hooff JP: Echography of the inferior vena cava is a simple and reliable tool for estimation of 'dry weight' in haemodialysis patients. Nephrol Dial Transplant 1989, 4:563-568.

24. Guiotto G, Masarone M, Paladino F, Ruggiero E, Scott S, Verde S, Schiraldi F: Inferior vena cava collapsibility to guide fluid removal in slow continuous ultrafiltration: a pilot study. Intensive Care Med 2010, 36:692-696.

25. Vieillard-Baron A, Prin S, Chergui K, Dubourg O, Jardin F: Echo-Doppler demonstration of acute cor pulmonale at the bedside in the medical intensive care unit. Am J Respir Crit Care Med 2002, 166:1310-1319.

26. Vanoverschelde JL, Robert AR, Gerbaux A, Michel X, Hanet C, Wijns W: Noninvasive estimation of pulmonary arterial wedge pressure with Doppler transmitral flow velocity pattern in patients with known heart disease. Am J Cardiol 1995, 75:383-389.

27. Boussuges A, Blanc P, Molenat F, Burnet H, Habib G, Sainty JM: Evaluation of left ventricular filling pressure by transthoracic Doppler 
echocardiography in the intensive care unit. Crit Care Med 2002, 30:362-367.

28. Bouhemad B, Nicolas-Robin A, Benois A, Lemaire S, Goarin JP, Rouby JJ: Echocardiographic Doppler assessment of pulmonary capillary wedge pressure in surgical patients with postoperative circulatory shock and acute lung injury. Anesthesiology 2003, 98:1091-1100.

29. Mayo PH, Beaulieu Y, Doelken P, Feller-Kopman D, Harrod C, Kaplan A, Oropello J, Vieillard-Baron A, Axler O, Lichtenstein D Maury E, Slama M, Vignon P: American College of Chest Physicians/La Societe de Reanimation de Langue Francaise statement on competence in critical care ultrasonography. Chest 2009, 135:1050-1060.

30. Barbier C, Loubieres Y, Schmit C, Hayon J, Ricome JL, Jardin F, VieillardBaron A: Respiratory changes in inferior vena cava diameter are helpful in predicting fluid responsiveness in ventilated septic patients. Intensive Care Med 2004, 30:1740-1746.

31. Vieillard-Baron A, Chergui K, Rabiller A, Peyrouset O, Page B, Beauchet A, Jardin F: Superior vena caval collapsibility as a gauge of volume status in ventilated septic patients. Intensive Care Med 2004, 30:1734-1739.

32. Lewis JF, Kuo LC, Nelson JG, Limacher MC, Quinones MA: Pulsed Doppler echocardiographic determination of stroke volume and cardiac output: clinical validation of two new methods using the apical window. Circulation 1984, 70:425-431.

33. Dokainish H, Zoghbi WA, Lakkis NM, Al-Bakshy F, Dhir M, Quinones MA, Nagueh SF: Optimal noninvasive assessment of left ventricular filling pressures: a comparison of tissue Doppler echocardiography and B-type natriuretic peptide in patients with pulmonary artery catheters. Circulation 2004, 109:2432-2439.

34. Nagueh SF, Appleton CP, Gillebert TC, Marino PN, Oh JK, Smiseth OA, Waggoner AD, Flachskampf FA, Pellikka PA, Evangelisa A:

Recommendations for the evaluation of left ventricular diastolic function by echocardiography. Eur J Echocardiogr 2009, 10:165-193.

35. Vieillard-Baron A, Charron C, Chergui K, Peyrouset O, Jardin F: Bedside echocardiographic evaluation of hemodynamics in sepsis: is a qualitative evaluation sufficient? Intensive Care Med 2006, 32:1547-1552.

36. Ferrari E, Baudouy M, Taillan B, Fredenrich A, Tomi M, Grinda JM, Teboul J, Jourdan J, Morand P: Cardiac insufficiency caused by arteriovenous fistula. An unusual complication of spinal surgery. Arch Mal Coeur Vaiss 1990, 83:1727-1728, [Article in French].

37. Ray P, LeManach Y, Riou B, Houle T: Statistical evaluation of a biomarker. Anesthesiology 2010, 112:1023-1040.

38. Hanley JA, MCNeil BJ: A method of comparing the areas under receiver operating characteristic curves derived from the same cases. Radiology 1983, 148:839-843

39. Ray P, Le Manach Y, Riou B, Houle TT: Statistical Evaluation of a Biomarker. Anesthesiology 2010, , 112: 1023-1040.

40. Carpenter J, Bithell J: Bootstrap confidence intervals: when, which, what? A practical guide for medical statisticians. Stat Med 2000, 19:1141-1164.

41. Lyon M, Blaivas $M$, Brannam L: Sonographic measurement of the inferior vena cava as a marker of blood loss. Am J Emerg Med 2005, 23:45-50.

42. Baumann UA, Marquis C, Stoupis C, Willenberg TA, Takala J, Jakob SM: Estimation of central venous pressure by ultrasound. Resuscitation 2005, 64:193-199.

43. Wallace DJ, Allison M, Stone MB: Inferior vena cava percentage collapse during respiration is affected by the sampling location: an ultrasound study in healthy volunteers. Acad Emerg Med 2010, 17:96-99.

44. Kimura BJ, Dalugdugan R, Gilcrease GW, Phan JN, Showalter BK, Wolfson T: The effect of breathing manner on inferior vena caval diameter. Eur $J$ Echocardiogr 2011, 12:120-123.

45. Dokainish H, Nguyen J, Sengupta R, Pillai M, Alam M, Bobek J, Lakkis N: New, simple echocardiographic indexes for the estimation of filling pressure in patients with cardiac disease and preserved left ventricular ejection fraction. Echocardiography 2010, 27:946-953.

doi:10.1186/cc11672

Cite this article as: Muller et al:: Respiratory variations of inferior vena cava diameter to predict fluid responsiveness in spontaneously breathing patients with acute circulatory failure: need for a cautious use. Critical Care 2012 16:R188.

\section{Submit your next manuscript to BioMed Central and take full advantage of:}

- Convenient online submission

- Thorough peer review

- No space constraints or color figure charges

- Immediate publication on acceptance

- Inclusion in PubMed, CAS, Scopus and Google Scholar

- Research which is freely available for redistribution 